\title{
Albumin-bound paclitaxel for the treatment of refractory or relapsed small-cell lung cancer
}

\author{
HIRONORI YOSHIDA, YOUNG HAK KIM, HIROAKI OZASA, HIROKI NAGAI, YUICHI SAKAMORI, \\ TAKASHI NAKAOKU, YOSHITAKA YAGI, TAKAHIRO TSUJI, TAKASHI NOMIZO and MICHIAKI MISHIMA
}

Department of Respiratory Medicine, Graduate School of Medicine, Kyoto University, Kyoto 606-8507, Japan

Received September 25, 2015; Accepted March 8, 2016

DOI: $10.3892 / \mathrm{mco} .2016 .887$

\begin{abstract}
Since nanoparticle albumin-bound (nab)-paclitaxel exerts clinically meaningful antitumor effects on various malignancies, including breast, gastric and non-small-cell lung cancer, we hypothesized that treatment with nab-paclitaxel may also be beneficial for patients with small-cell lung cancer (SCLC). We herein evaluated the safety and efficacy of weekly, single-agent nab-paclitaxel in patients with refractory or relapsed SCLC. Between May, 2013 and February, 2015, 9 patients with refractory or relapsed SCLC were treated with single-agent nab-paclitaxel at the Kyoto University Hospital. The medical records of the patients were retrospectively reviewed. All the patients had been previously treated with $\geq 2$ lines of chemotherapy prior to receiving nab-paclitaxel. The median number of cycles of nab-paclitaxel was 2 (range, 1-4) and 3 partial responses were observed (response rate: $33 \%$ ). The toxicity was generally mild and manageable: Grade 3/4 adverse events were only observed in 1 patient (grade 3 leukopenia). Thus, weekly administration of nab-paclitaxel may be a viable treatment option in patients with refractory or relapsed SCLC. Considering that treatment options are quite limited in this patient population, further evaluation of this regimen may prove valuable in the clinical setting.
\end{abstract}

\section{Introduction}

Although small-cell lung cancer (SCLC) is initially highly sensitive to chemotherapy and radiotherapy, the majority of the patients eventually experience disease relapse and their prognosis is generally poor. To date, topotecan is the only Food and Drug Administration-approved drug for relapsed or refractory SCLC. In Japan, amrubicin is also available; however, the overall treatment options for such patients is limited.

Correspondence to: Dr Young Hak Kim, Department of Respiratory Medicine, Graduate School of Medicine, Kyoto University, 54 Shogoin-Kawaharacho, Sakyo-ku, Kyoto 606-8507, Japan

E-mail: ekim@kuhp.kyoto-u.ac.jp

Key words: small-cell lung cancer, chemotherapy, refractory, relapsed, nanoparticle albumin-bound paclitaxel
Previous phase II studies have demonstrated that paclitaxel has antitumor activity in patients with pretreated SCLC (1). Recently, nanoparticle albumin-bound (nab)-paclitaxel (Abraxane ${ }^{\circledR}$; Taiho, Tokyo, Japan) was developed to improve the therapeutic index of paclitaxel, and randomized studies have confirmed that nab-paclitaxel was more effective and exhibited a more favorable safety profile compared with conventional solvent-based paclitaxel (2).

In this study, based on this background, we retrospectively reviewed 9 patients with refractory or relapsed SCLC who were treated with nab-paclitaxel at Kyoto University Hospital.

\section{Patients and methods}

Patients. Between May, 2013 and February,2015, 64 patients with thoracic malignancies were treated with nab-paclitaxel. Of those patients, 8 had thymic tumors, 47 had non-small-cell lung cancer (NSCLC) and 9 had SCLC. Nab-paclitaxel $\left(100 \mathrm{mg} / \mathrm{m}^{2}\right)$ was administered on days 1,8 , and 15 of a 28-day cycle. Tumor response was evaluated by using the Response Evaluation Criteria in Solid Tumors, version 1.1 (3), and adverse events were graded by using the Common Terminology Criteria for Adverse Events, version 4.0 (http://ctep.cancer.gov/protocolDevelopment/electronic_applications/ctc.htm\#ctc_40; http:// ctep.cancer.gov/protocolDevelopment/ electronic_applications/ctc.htm\#ctc_40\%3E*).

Type of relapse. In this study, sensitive relapse was defined as patients who responded to initial chemotherapy and developed disease recurrence $>3$ months after the completion of chemotherapy, whereas refractory relapse was defined as patients who did not respond to initial chemotherapy or developed disease recurrence within 3 months after the completion of chemotherapy.

\section{Results}

Patient characteristics. The patient characteristics are summarized in Table I. The median age of the patients was 67 years (range, 60-76 years) and our sample included 6 men and 3 women. The performance status was 0 in 4,1 in 3 , and 2 in 2 patients. All the patients had been previously treated with $\geq 2$ lines of chemotherapy prior to receiving nab-paclitaxel (range, 2-9 lines). A total of 5 patients were 
Table I. Patient characteristics at time of nab-paclitaxel administration $(n=9)$.

\begin{tabular}{|c|c|c|c|c|c|c|c|c|}
\hline Patient & $\begin{array}{c}\text { Age } \\
\text { (years) }\end{array}$ & Gender & $\begin{array}{c}\text { PS } \\
(\mathrm{ECOG})\end{array}$ & $\begin{array}{c}\text { Disease } \\
\text { extent }\end{array}$ & $\begin{array}{l}\text { No. of previous } \\
\text { chemotherapy } \\
\text { regimens }\end{array}$ & $\begin{array}{c}\text { No. of } \\
\text { nab-paclitaxel } \\
\text { cycles }\end{array}$ & $\begin{array}{l}\text { Sensitivity to } \\
\text { first-line } \\
\text { chemotherapy }\end{array}$ & $\begin{array}{l}\text { Previous } \\
\text { paclitaxel } \\
\text { treatment }\end{array}$ \\
\hline 1 & 69 & Male & 1 & $\mathrm{ED}$ & 9 & 4 & Sensitive & Yes \\
\hline 2 & 73 & Male & 0 & LD & 6 & 2 & Sensitive & Yes \\
\hline 3 & 65 & Female & 2 & ED & 2 & 2 & Refractory & No \\
\hline 4 & 68 & Male & 1 & ED & 5 & 4 & Sensitive & No \\
\hline 5 & 76 & Male & 0 & LD & 5 & 4 & Sensitive & Yes \\
\hline 6 & 56 & Female & 1 & ED & 2 & 2 & Sensitive & No \\
\hline 7 & 67 & Male & 0 & ED & 2 & 1 & Refractory & No \\
\hline 8 & 64 & Male & 0 & $\mathrm{ED}$ & 2 & 1 & Refractory & No \\
\hline 9 & 60 & Female & 2 & ED & 3 & 1 & Refractory & No \\
\hline
\end{tabular}

Nab, nanoparticle albumin-bound; PS, performance status; ECOG, Eastern Cooperative Oncology Group; LD, limited disease; ED, extensive disease.
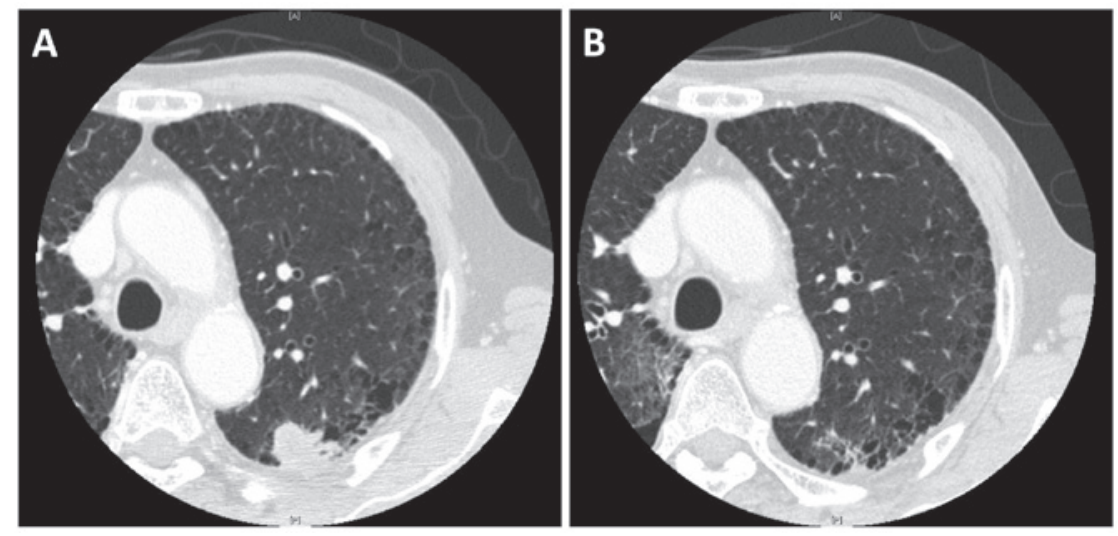

Figure 1. Representative case responding to nanoparticle albumin-bound (nab)-paclitaxel following failure of solvent-based paclitaxel. Chest computed tomography images (A) prior to receiving nab-paclitaxel and (B) after two cycles of nab-paclitaxel; the nodule in the left upper pulmonary lobe has almost disappeared.

Table II. Antitumor response.

\begin{tabular}{lcr}
\hline Type of response & No. of patients & $\%$ \\
\hline Complete response & 0 & 0 \\
Partial response & 3 & 33 \\
Stable disease & 0 & 0 \\
Progressive disease & 4 & 45 \\
Not evaluable & 2 & 22 \\
Overall response rate & 3 & 33
\end{tabular}

classified as sensitive relapse and the remaining 4 as refractory relapse. Three patients had been previously treated with solvent-based paclitaxel.

Response. There were 3 partial responses (response rate: $33 \%$ ) and a representative case is shown in Fig. 1. Among these 3 patients, all 3 were classified as sensitive relapse and 2 had been pretreated with solvent-based paclitaxel, both of whom achieved partial response after two cycles, but their disease progressed after four cycles of solvent-based paclitaxel. The median number of cycles of nab-paclitaxel was 2 (range, 1-4 cycles). The 2 non-evaluable cases were due to deterioration of epilepsy, without central nervous system metastases, in one case, and lack of adequate radiographic follow-up in the other case (Table II).

Toxicity. The toxicities of nab-paclitaxel are summarized in Table III. Of the 9 patients, only 1 developed a grade 3 event (leukopenia); no other grade 3/4 adverse events hematological or non-hematological, were observed. One patient required a dose reduction due to fatigue, but no treatment discontinuation was required.

\section{Discussion}

Despite an initial good response to chemotherapy, almost all SCLC patients experience relapse. To date, a number of studies on salvage chemotherapy have been conducted, and some demonstrated a clinical benefit. For example, topotecan prolonged survival time and improved quality of life compared with supportive care alone (4), and amrubicin exhibited efficacy 
Table III. Summary of toxicities.

\begin{tabular}{|c|c|c|c|c|c|}
\hline Toxicity & Grade 1 & Grade 2 & Grade 3 & Grade 4 & Grade $3 / 4(\%)$ \\
\hline Leukopenia & 1 & 2 & 1 & 0 & $1(11)$ \\
\hline Neutropenia & 2 & 1 & 0 & 0 & $0(0)$ \\
\hline Anemia & 2 & 3 & 0 & 0 & $0(0)$ \\
\hline Thrombocytopenia & 0 & 0 & 0 & 0 & $0(0)$ \\
\hline Mucositis & 2 & 0 & 0 & 0 & $0(0)$ \\
\hline Nausea & 1 & 0 & 0 & 0 & $0(0)$ \\
\hline Vomiting & 0 & 0 & 0 & 0 & $0(0)$ \\
\hline Diarrhea & 1 & 0 & 0 & 0 & $0(0)$ \\
\hline Constipation & 4 & 0 & 0 & 0 & $0(0)$ \\
\hline Fatigue & 6 & 1 & 0 & 0 & $0(0)$ \\
\hline Neuropathy & 4 & 1 & 0 & 0 & $0(0)$ \\
\hline Myalgia & 1 & 0 & 0 & 0 & $0(0)$ \\
\hline
\end{tabular}

comparable to that of topotecan (5). However, it is clear that the treatment options remain quite limited. Nab-paclitaxel has been approved for the treatment of NSCLC, but its efficacy against SCLC remains unknown.

In this study, we aimed to report the efficacy and toxicity of nab-paclitaxel for relapsed or refractory SCLC. Although all the patients were heavily pretreated, 3 patients achieved partial response with nab-paclitaxel. Interestingly, 2 patients who developed disease progression after weekly solvent-based paclitaxel treatment responded to nab-paclitaxel. In in vitro and mouse models, at an equitoxic dose, nab-paclitaxel-treated groups exhibited more complete regressions, longer time to recurrence, longer doubling time and prolonged survival, compared with solvent-based paclitaxel (6). In addtion, at an equal dose, intratumoral accumulation of paclitaxel was $33 \%$ higher for nab-paclitaxel vs. solvent-based paclitaxel (6). These results were consistent with the results of clinical trials of breast cancer (2) and NSCLC (7), and our study suggested the superiority of the nab-paclitaxel to solvent-based paclitaxel in SCLC as well.

In conclusion, our findings suggest that weekly administration of nab-paclitaxel may be a useful treatment option for refractory or relapsed SCLC. However, further investigation of nab-paclitaxel, alone or in combination with other agents, for SCLC is warranted.

\section{References}

1. Yamamoto N, Tsurutani J, Yoshimura N, Asai G, Moriyama A, Nakagawa K, Kudoh S, Takada M, Minato Y and Fukuoka M: Phase II study of weekly paclitaxel for relapsed and refractory small cell lung cancer. Anticancer Res 26: 777-781, 2006.
2. Gradishar WJ, Tjulandin S, Davidson N, Shaw H, Desai N, Bhar P, Hawkins M and O'Shaughnessy J: Phase III trial of nanoparticle albumin-bound paclitaxel compared with polyethylated castor oil-based paclitaxel in women with breast cancer. J Clin Oncol 23: 7794-7803, 2005.

3. Eisenhauer EA, Therasse P, Bogaerts J, Schwartz LH, Sargent D, Ford R, Dancey J, Arbuck S, Gwyther S, Mooney M, et al: New response evaluation criteria in solid tumours: revised RECIST guideline (version 1.1). Eur J Cancer 45: 228-247, 2009.

4. O'Brien ME, Ciuleanu TE, Tsekov H, Shparyk Y, Cuceviá B, Juhasz G, Thatcher N, Ross GA, Dane GC and Crofts T: Phase III trial comparing supportive care alone with supportive care with oral topotecan in patients with relapsed small-cell lung cancer. J Clin Oncol 24: 5441-5447, 2006.

5. von Pawel J, Jotte R, Spigel DR, O'Brien ME, Socinski MA, Mezger J, Steins M, Bosquée L, Bubis J, Nackaerts K, et al: Randomized phase III trial of amrubicin versus topotecan as second-line treatment for patients with small-cell lung cancer. J Clin Oncol 32: 4012-4019, 2014.

6. Desai N, Trieu V, Yao Z, Louie L, Ci S, Yang A, Tao C, De T, Beals B, Dykes D, et al: Increased antitumor activity, intratumor paclitaxel concentrations and endothelial cell transport of cremophor-free, albumin-bound paclitaxel, ABI-007, compared with cremophor-based paclitaxel. Clin Cancer Res 15: 1317-1324, 2006.

7. Socinski MA, Bondarenko I, Karaseva NA, Makhson AM, Vynnychenko I, Okamoto I, Hon JK, Hirsh V, Bhar P, Zhang $\mathrm{H}$, et al: Weekly nab-paclitaxel in combination with carboplatin versus solvent-based paclitaxel plus carboplatin as first-line therapy in patients with advanced non-small-cell lung cancer: Final results of a phase III trial. J Clin Oncol 30: 2055-2062, 2012. 